$$
\begin{aligned}
& \text { CONF-960646-22 } \\
& \text { ANL/TD/CP-.89123 }
\end{aligned}
$$

\title{
The Fabrication of a Vanadium-Stainless Steel Test Section for MHD Testing of Insulator Coatings in Flowing Lithium
}

\author{
Claude B. Reed, Richard F Mattas, Dale L. Smith, Hee Chung, \\ and Hanchung Tsai \\ Fusion Power Program, Argonne National Laboratory
}

G. D. Morgan and G. W. Wille

High Energy Systems, McDonnell Douglas Aerospace

W. R. Johnson

Fusion Division, General Atomics

Conrad Young

Century Tubes

$\log \# \mathbf{e 2 0 8}$ :

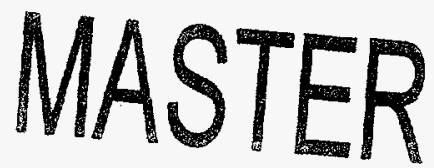

DISTRIBUTION OF ThIS DOCUMENT BS UMLMTED

The submited manuscript has been authored
by a contractor of the U.S. Government
under contrac: No. W-31-109-ENG-38.
Accordingly, the U.S. Government yetains a
nonexclusive, royalty-free license to publish or
reproduce the published form of this
contribution, or allow athers to do so. for U.S.
Government purposes.

Ma

Presented at the 12th Topical Meeting on the Technology of Fusion Energy June 16-20, 1996 Reno Nevada 


\section{DISCLAIMER}

This report was prepared as an account of work sponsored by an agency of the United States Government. Neither the United States Government nor any agency thereof, nor any of their employees, makes any warranty, express or implied, or assumes any legal liability or responsibility for the accuracy, completeness, or usefulness of any information, apparatus, product, or process disclosed, or represents that its use would not infringe privately owned rights. Reference herein to any specific commercial product, process, or service by trade name, trademark, manufacturer, or otherwise does not necessarily constitute or imply its endorsement, recommendation, or favoring by the United States Government or any agency thereof. The views and opinions of authors expressed herein do not necessarily state or reflect those of the United States Government or any agency thereof. 


\section{DISCLAIMER}

Portions of this document may be illegible in electronic image products. Images are produced from the best available original document. 


\section{THE FABRICATION OF A VANADIUM-STAINLESS STEEL TEST SECTION FOR MHD TESTING OF INSULATOR COATINGS IN FLOWING LITHIUM}

\author{
C. B. Reed, R. F. Mattas, D. L. Smith, \\ H. Chung, and H.-C. Tsai \\ Argonne National Laboratory \\ 9700 South Cass Avenue \\ Argonne, Illinois 60439 \\ W. R. Johnson \\ General Atomics \\ P.O. Box 85608 \\ San Diego, California 92186
}

\section{ABSTRACT}

To test the magnetohydrodynamic (MHD) pressure drop reduction performance of candidate insulator coatings for the ITER Vanadium/Lithium Breeding Blanket, a test section comprised of a $\mathrm{V}-4 \mathrm{Cr}-4 \mathrm{Ti}$ liner inside a stainless steel pipe was designed and fabricated. Theoretically, the MHD pressure drop reduction benefit resulting from an electrically insulating coating on a vanadium-lined pipe is identical to the benefit derived from an insulated pipe fabricated of vanadium alone. A duplex test section design consisting of a $\mathrm{V}$ alloy liner encased in a SS pressure boundary provided protection for vanadium from atmospheric contamination during operation at high temperature and obviated any potential problems with vanadium welding while also minimizing the amount of $\mathrm{V}$ alloy material required.

From the MHD and insulator coating point of view, the test section outer SS wall and inner $V$ alloy liner can be modeled simply as a wall having a sandwich construction.

Two $52.3 \mathrm{~mm}$ OD $\times 2.9 \mathrm{~m}$ long $\mathrm{V}$-alloy tubes were fabricated by Century Tubes from $64 \mathrm{~mm} \times 200 \mathrm{~mm} \times$ $1245 \mathrm{~mm}$ extrusions produced by Teledyne Wah Chang. The test section's duplex structure was subsequently fabricated at Century Tubes by drawing down a SS pipe ( 2 inch schedule 10 ) over one of the $53.2 \mathrm{~mm}$ diameter $\mathrm{V}$ tubes.

\section{INTRODUCTION}

To test the MHD pressure drop reduction performance of candidate insulator coatings for the ITER Vanadium/Lithium Breeding Blanket, a test section having a $\mathrm{V}-4 \mathrm{Cr}-4 \mathrm{Ti}$ inner liner with a stainless steel cladding was designed and fabricated. Vanadium-base alloys have significant advantages over other candidate alloys

\author{
G. D. Morgan and G. W. Wille \\ High Energy Systems \\ McDonnell Douglas Aerospace \\ P.O. Box 516 \\ St. Louis, Missouri 63166 \\ C. Young \\ Century Tubes, Inc. \\ 7910 Dunbrook Rd. \\ San Diego, California 92126
}

(such as austenitic and ferritic steels) for use as structural materials in fusion devices. In the past, extensive investigations have been conducted on the swelling behavior, tensile properties, impact toughness, and microstrictural evolution of V, V-Ti, V-Cr, V-Cr-Ti, and V-Ti-Si alloys after irradiation by fast neutrons at $420^{\circ} \mathrm{C}-600^{\circ} \mathrm{C}$. These investigations revealed that $\mathrm{V}-\mathrm{Cr}$ - $\mathrm{Ti}$ alloys containing $\approx 4$ wt.\% Cr, $\approx 4$ wt. \% Ti, 400-1000 wt. ppm Si, and $<1000$ wt. ppm $\mathrm{O}+\mathrm{N}+\mathrm{C}$ were the most promising yanadiumbased candidate alloy for application in fusion reactor structural components because they exhibit superior physical and mechanical properties. ${ }^{1}$ Hence, $\mathrm{V}-4 \mathrm{Cr}-4 \mathrm{Ti}$ was the material of choice for the inner liner.

The test section ID/OD were $48.4 / 58.6 \mathrm{~mm}$; the wall thickness' of the vanadium liner/stainless steel pressure boundary were $2.3 / 2.8 \mathrm{~mm}$. The $\mathrm{V}$ liner occupied the central $2.9 \mathrm{~m}$ of the $3.5 \mathrm{~m}$ test section length. The starting vanadium extrusion was produced by Teledyne Wah Chang; Century Tubes performed the fabrication steps necessary to produce the vanadium liner/stainless steel duplex structure; ANL developed the overall test section design and an outline of the fabrication steps; preparation of the detailed manufacturing plan and dayto-day manufacturing follow was provided by McDonnell Douglas Aerospace. General Atomics provided special assistance and metallurgical expertise for certain fabrication problems. Further fabrication details, including numerous photographs, metallographic sections, and additional data can be found in Ref. [2].

The fabrication began with a $62.2 \mathrm{~mm} \times 63.5 \mathrm{~mm}$ $\times 1245 \mathrm{~mm}$ bar which was saw cut from a $\sim 64 \mathrm{~mm} \times$ $200 \mathrm{~mm} \times 1245 \mathrm{~mm}$ extrusion. The bar was turned to a $61 \mathrm{~mm}$ dia. $\times 1245$ long round, which was gun-drilled to produce a thick walled tube. Several cold drawing steps, each followed by cleaning and a vacuum anneal, were performed to produce a liner with the desired dimensions. 


\section{DESIGN DESCRIPTION OF V/SS MHD TEST SECTION}

Figure 1 is a fabrication drawing of the V/SS duplex test section, intended for MHD testing of insulator coating materials in flowing liquid lithium in the Argonne Liquid Metal Experiment (ALEX). The test section ID/OD were $48.4 / 58.6 \mathrm{~mm}$; the wall thickness' of the vanadium liner/stainless steel pressure boundary were $2.3 / 2.8 \mathrm{~mm}$. The $\mathrm{V}$ liner occupied the central $2.9 \mathrm{~m}$ of the $3.5 \mathrm{~m}$ test section length. The lithium pressure boundary is a $60 \mathrm{~mm}$ dia. $3045 \mathrm{~S}$ pipe ( 2 inch schedule 10) welded to schedule 10300 series SS eccentric reducers; all welding was performed to the ASME B\&PV Code. The end flanges, which were welded to eccentric reducers, and which connect the test section to ALEX loop piping, are a proprietary design (OTECO ${ }^{\otimes}$, Inc.), having a metal-to-metal seal between two $316 \mathrm{SS}$ hubs using a 17-4 PH SS seal ring; their pressure and temperature ratings are $12.7 \mathrm{MPa} ; 540^{\circ} \mathrm{C}$, respectively. OTECO flanged connections have been successfully used previously in ALEX at $0.14 \mathrm{MPa} ; 200^{\circ} \mathrm{C} \mathrm{NaK}$. The present application, at $33 \mathrm{kPa}$ and $550^{\circ} \mathrm{C} \mathrm{Li}$, resulted in no leaks.

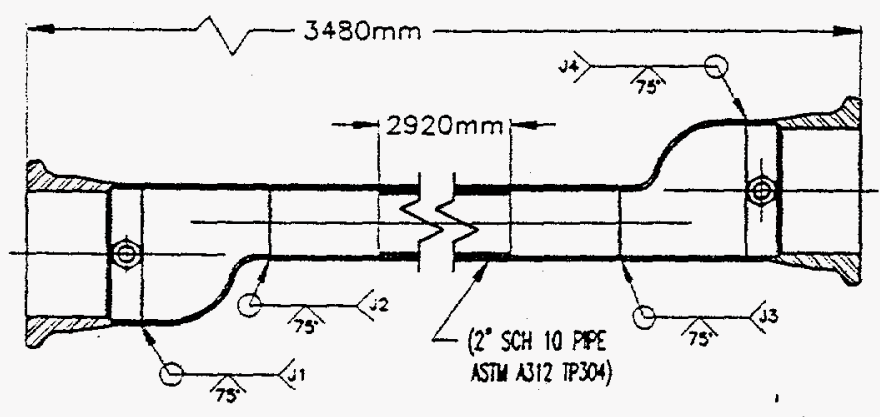

Figure 1. V/SS duplex test section.

\section{DESCRIPTION OF V-ALLOY STARTING MATERIAL}

The starting point in the fabrication of the vanadium alloy liner material was a rectangular bar, $1245 \mathrm{~mm}$ in length; one of several long bars $\approx 64 \mathrm{~mm}$ in thickness and $\approx 200 \mathrm{~mm}$ in width, extruded from a $500-\mathrm{kg}$ ingot of $\mathrm{V}-4 \mathrm{Cr}-4 \mathrm{Ti}$ (heat No. 832665 , produced by Teledyne Wah Chang Albany). The ingot was produced by multiple vacuum-arc melting using screened high-quality raw materials of vanadium, chrome, and titanium.

The specification of the chemical composition of the heat had been carefully determined to reflect the experience and knowledge gained from fabrication, testing, and microstructural examination of laboratoryscale heats of $\mathrm{V}-\mathrm{Ti}$ and $\mathrm{V}-\mathrm{Cr}-\mathrm{Ti}$ alloys. Particular attention was paid to control of the following impurities: $\mathrm{Nb}, \mathrm{Mo}, \mathrm{Cu}, \mathrm{Si}, \mathrm{O}, \mathrm{N}, \mathrm{C}, \mathrm{S}, \mathrm{P}, \mathrm{Cl}, \mathrm{Ca}, \mathrm{K}, \mathrm{Na}$, and $\mathrm{B}$. The final specification of ingot chemistry is given in Table 1.
Table 1. Chemical composition (impurities in wppm) of the industrial-scale $\left(500 \mathrm{~kg}\right.$ ) heat of $\mathrm{V}-4 \mathrm{Cr}-4 \mathrm{Ti}^{\mathrm{a}}$ ingot.

\begin{tabular}{lcc}
\hline Element & Spec. & Pos. $1-3$ \\
\hline & & \\
$\mathrm{Cr}$ & $4 \pm 0.5$ wt.\% & $3.72-3.83$ \\
$\mathrm{Ti}$ & $4 \pm 0.5$ wt.\% & $3.79-4.16$ \\
$\mathrm{Cu}$ & $<10$ & $<50$ \\
$\mathrm{Si}$ & $400-1000$ & $720-840$ \\
$\mathrm{O}$ & $<400$ & $280-360$ \\
$\mathrm{~N}$ & $<200$ & $80-93$ \\
$\mathrm{C}$ & $<200$ & $64-94$ \\
$\mathrm{~S}$ & $<10$ & $<10$ \\
$\mathrm{P}$ & $<10$ & $<30$ \\
$\mathrm{Ca}$ & $<2$ & $<10$ \\
$\mathrm{Cl}$ & $<$ & $<5-7 \ldots$ \\
$\mathrm{B}$ & $<200$ & - \\
$\mathrm{Al}$ & $<10$ & - \\
$\mathrm{Nb}$ & $<200$ & - \\
$\mathrm{Fe}$ & $<10$ & \\
$\mathrm{Mo}$ & &
\end{tabular}

${ }^{2}$ Determined from 3 different positions in the $64-\mathrm{mm}$ thick and 200-mm-wide extruded bar.

Local inhomogeneity of $\mathrm{Cr}$ and $\mathrm{Ti}$ was specified not to exceed $\pm 0.3 \mathrm{wt} . \%$. Only low-chlorine ( $<5$ wppm) double- or triple-melted titanium feedstock was used in making the ingot.

The results of chemical analyses, averaged over three measurements on the 63-mm-thick extruded bars, are also given in Table 1.

The procedures for ingot extrusion were specified to closely reproduce procedures used in fabricating an excellent laboratory heat of $\mathrm{V}-4 \mathrm{Cr}-4 \mathrm{Ti}$ (ANL ID BL47). Specifically, the machined cast ingot was encased in an evacuated stainless jacket and extruded at $1150^{\circ} \mathrm{C}$ into bar with a nominal thickness of $63.5 \mathrm{~mm}$ (2.5 in.).

The satisfactory chemical composition of the ingot, and the results of Charpy-impact tests showing that mechanical properties of the large-scale heat were as good as those of laboratory-scale heats, provided assurance that heat No. 832665 of $\mathrm{V}-4 \mathrm{Cr}-4 \mathrm{Ti}$ possessed the same desirable properties as the most promising vanadium-based candidate alloy for application in fusion reactor structural components.

\section{INITIAL FABRICATION PLAN}

Starting with the above described $\sim 64 \mathrm{~mm} \times 200$ $\mathrm{mm} \times 1245 \mathrm{~mm} V$ alloy bar, the initial fabrication plan consisted of the following four main phases: 
$\checkmark$ alloy tube blank preparation

saw cutting

lathe machining

gun drilling

cleaning

annealing

\section{$V$ alloy liner drawing steps}

five cold drawing steps, $-10 \%$ reduction, each cleaning

annealing

six cold drawing steps, $\sim 10 \%$ reduction, each

cleaning

annealing

QA

\section{$\checkmark$ alloy liner expansion steps}

three cold expansion steps, $\sim 5 \%$ dia. incr., each

cleaning

annealing

one cold expansion step, $\sim 5 \%$ dia. increase

cleaning

insert liner into pipe

two cold expansion steps, $\sim 5 \%$ dia. increase, each

cleaning

\section{ACTUAL FABRICATION STEPS}

See Table 2 for a summary of the actual fabrication steps followed, and described below.

The first phase of the fabrication plan, $\mathrm{V}$ alloy tube blank preparation, was followed closely; two smaller bars of dimensions $-62.2 \mathrm{~mm} \times 63.5 \mathrm{~mm} \times 1245 \mathrm{~mm}$ each were saw cut from the starting bar. These roughly square bars were lathe machined to $61 \mathrm{~mm}$ OD $\times 1245$ $\mathrm{mm}$ long round bars and subsequently gun drilled to produce $61 \mathrm{~mm}$ OD $\times 47.6 \mathrm{~mm}$ ID $\times 1245 \mathrm{~mm}$ long tube blanks. The resulting IDs were quite rough, with very pronounced grooves (perhaps 500 microinches), resulting from the softness of the material. The grooves disappeared following subsequent drawing operations.

The tube blanks were subsequently cleaned by first degreasing and then immersing them in a 30 v/o Nitric Acid - 3 v/o Hydrofluoric Acid solution at room temperature for 15 minutes. Tubing ODs were checked before and after this cleaning step and no dimensional changes were found. All cleaning steps were as described.

Finally, the tube blanks were vacuum annealed at $1025^{\circ} \mathrm{C}$ for one hour at less than $1 \times 10^{-5}$ torr. Support fixtures and a "tent," to prevent or minimize contamination of the tubes in the furnace during the anneal, were fabricated from Ti-6Al-4V. All annealing steps were as described in Table 2.
Table 3. Actual V/SS tube fabrication outline.

\begin{tabular}{|c|c|c|c|c|c|}
\hline \multirow{3}{*}{\multicolumn{3}{|c|}{ Tubo blank preperation }} & \multirow{2}{*}{$\begin{array}{c}-X \text { AREA } \\
\text { REOUCION }\end{array}$} & \multicolumn{2}{|c|}{ Comments } \\
\hline & & & & Fuoe? & Tute 2 \\
\hline & & & & & \\
\hline & a) & sew cutting & & $62.2 \times 63.3$ & $1245 \mathrm{~mm}$ bar \\
\hline & bl: & Lethe machining & & st dia $\times 1$ & $5 \mathrm{~mm}$ long bas \\
\hline & & gun drilling & & $8100 \times 47.8$ & $\times 1245 \mathrm{~mm}$ tube \\
\hline & dL & 1st cloening & & 30 v/O HNOS - & WO HF. $15 \mathrm{~min}$. AT \\
\hline & •) & ist annoul & & nominal & nominal \\
\hline & & & & & \\
\hline 2. & Firs: & draw oyclo & & 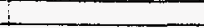 & \\
\hline & & cold draw 1.1 & 10 & nominal & nominal \\
\hline & & cold draw i 1.2 & 10 & nominal & nominal \\
\hline & & cold draw *1.3 & 10 & nominal & detects \\
\hline & & cold draw $+1,4$ & 10 & nominal & doloces \\
\hline & $0 !$ & 2nd cloaning & & 30 vo HNO3- & $10 \mathrm{HF}, 15 \mathrm{~min}, \mathrm{RT}$ \\
\hline & 1) & 2nd annoal & & discoloration & discoloration \\
\hline & & & & i & \\
\hline 3. & sog & ond draw cyclo & & 1 & \\
\hline & & cold draw 12.1 & 10 & nominal & defocts \\
\hline & b) & cold draw 12.2 & 10 & nominal & dotects \\
\hline & & cold draw 12.3 & 10 & nominal & defects \\
\hline & d) & 3 ded derning & & 30 w/o HNO3 - & $10 \mathrm{HF} .15 \mathrm{~min} . \mathrm{RT}$ \\
\hline & .) 1 & 3 d annoal & & suspect & Juish tinge \\
\hline & & & & $i$ & \\
\hline 4. & Thir & d draw sycio & & $t$ & \\
\hline & a) & cold draw 3,1 & 10 & $\begin{array}{c}\text { OOND circumferential } \\
\text { surtace cractiong }\end{array}$ & $\begin{array}{c}\text { OONo circumberential } \\
\text { surtace crecting }\end{array}$ \\
\hline & b) & cold draw $\$ 3.2$ & 10 & $\begin{array}{c}\text { OOAD eireumferential } \\
\text { surface crecking }\end{array}$ & $\begin{array}{c}\text { OOND circumlerential } \\
\text { surface ersecking }\end{array}$ \\
\hline & c) & cold draw $* 3,3$ & 10 & $\begin{array}{c}\text { OOnD circumferential } \\
\text { surtace eracking }\end{array}$ & $\begin{array}{l}\text { OOND circumforomtial } \\
\text { surface cracking }\end{array}$ \\
\hline & d)! & 4th eleaning & & 30 v/o HNO3. & to HF, $15 \mathrm{~min}, \mathrm{RT}$ \\
\hline & a) 1 & Ith arnoel & & suspoct, - 100 & torr, discoloration \\
\hline & & & & I & \\
\hline 5. & Firs & texpension gycle & & 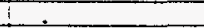 & \\
\hline & & expansion $* 1.1$ & & not performed & tongitudinal cracks \\
\hline & & & & T & \\
\hline & 103 & oning & & $-0.2 \mathrm{~mm}$ removed & $-0.2 \mathrm{~mm}$ rentroved \\
\hline & & & & ! & \\
\hline 7. & $\infty$ & Centeriess grinding & & $-0.1 \mathrm{~mm}$ removed & to.1 $\mathrm{mm}$ removed \\
\hline & & & & $I$ & \\
\hline 8. & $S e 0$ & and expension gycl & & $i$ & \\
\hline & a): & oxpansion $\# 2,1$ & & nol periorned & nominal \\
\hline & b) & expansion $\# 2.2$ & & sot pertormed & $\begin{array}{l}\text { longitudinal cracking } \\
\text { discontinued }\end{array}$ \\
\hline & & & & 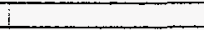 & \\
\hline 9. & $5 s$ & outer thbe cold worn & & 1 & \\
\hline & a)! & oxpansion & & nominal & net performed \\
\hline & b) & shrink/swaging & & nominal & not performed \\
\hline & & & & $i$ & \\
\hline 10. & End & flange welding & & nominal & nominal \\
\hline
\end{tabular}

Following the first annealing step, the tube blanks were put through the first draw cycle, see Table 2 . For this part of the fabrication, a mandrel is first inserted into the tube, and hammered in using a light sledge until the forward end of the mandrel exits the front end of the tube. Then the tube is swabbed with die lubricant (a plastic material contained in a solvent which after drying leaves a thin acetone-soluble plastic film on the tube), and pulled through the die (see Fig. 2). The mandrel is then removed.

During the second drawing step, two bands of discoloration or different structure along the length of one tube blank (Tube \#2), approximately $6 \mathrm{~mm}$ wide and 180 degrees apart, were noted. After 3 of the 5 specified draws ( $-30 \%$ reduction, specified to go to $-50 \%$ before annealing, see Table 2 ) in this drawing cycle, both tubes were performing very well, with a very nice external appearance. During the 4 th draw on Tube \#2, however, 
tlaws began to form about $40 \%$ into the draw, starting as a series of roughly parallel, small, slightly visible, $\sim 1 \mathrm{~mm}$ long, wavy transverse cracks or tears, reaching a maximum size of $-19 \mathrm{~mm}$ long by $-3 \mathrm{~mm}$ wide at about $60 \%$ into the draw, finally decreasing in size to about that of the initial small cracks at about $80 \%$ into the draw, and then disappearing. A virtual mirror image of this same cracking pattern was observable on the reverse side of the tube, -180 degrees away (see Fig. 3). The largest tears had fractured surfaces that were black in coloration and extended from the OD to the ID of the tube on both sides.

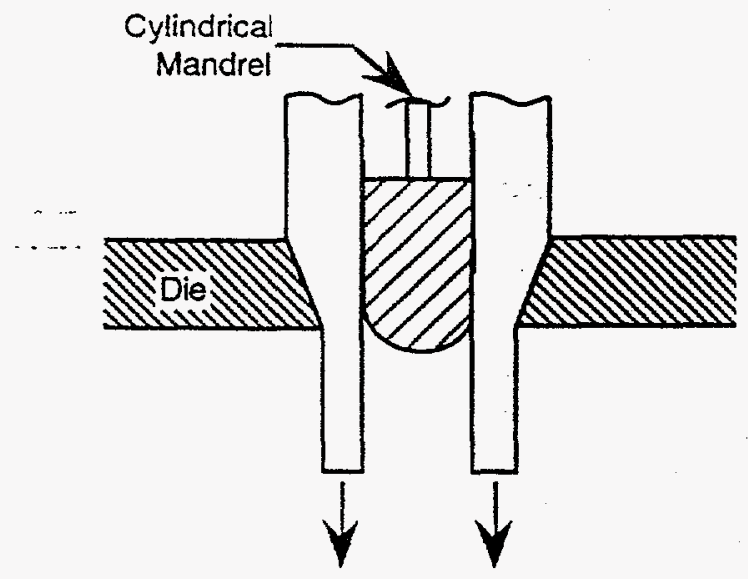

Figure 2. Tube drawing operation.
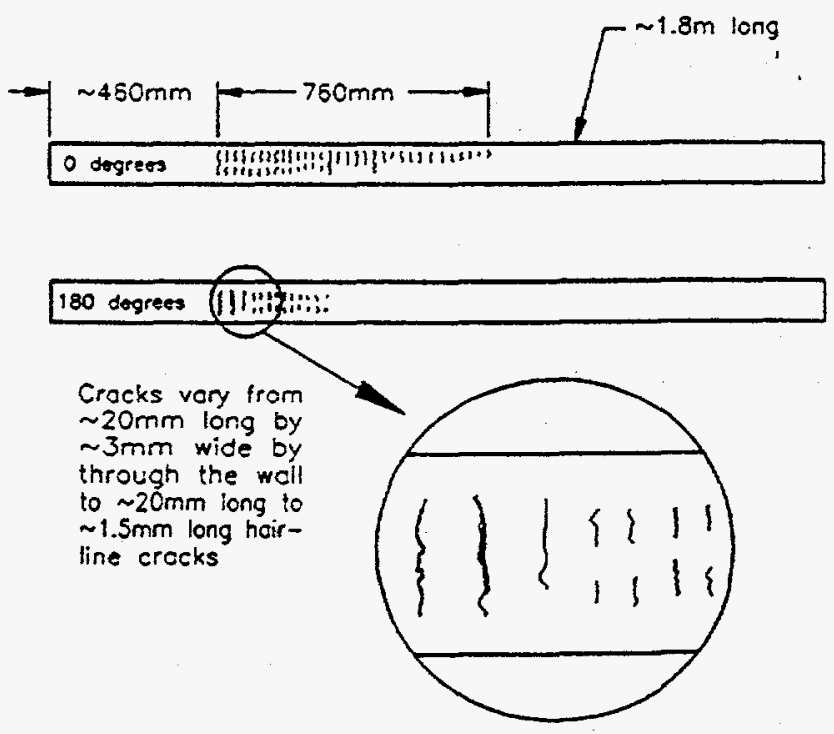

Figure 3. Defect locations in Tube \#2 after 2 nd anneal.
Additional visual observations revealed the same "bands" mentioned above, again 180 degrees apart on both sides of the tube, about $25 \mathrm{~mm}$ wide extending along the tube from $-1 / 4$ length point to midpoint. The defects of course were within these bands. The bands could have resulted from grain size differences, segregation, impurity banding, etc. The rest of the tube looked very good.

The cracks appeared to be the result of a localized exhaustion in the material's ductility due to a variation in its as-received structure, i.e., a variation in grain size the grain size of the starting material in the vicinity of the defected areas was large, probably in the range of 2-3 (ASTM)], inclusions, impurity and/or alloying addition segregation, hot work, and/or other difference in microstructure (e.g., some remaining cast structure perhaps). The problem appeared to result from a large inhomogeneity in the starting materials, apparently not present in the other tube blank.

The drawing operations were stopped at that point. The defects were partially spot-ground, especially the edges of the larger defects, so the tube would continue to draw, and both tubes were cleaned and annealed a second time. Following the second cleaning and annealing operations, both tubes were given a thorough visual examination. As before, Tube \#1 still looked good, with many, but only minor longitudinal die marks (e.g., like fine scratches) visible on its surface. The defected tube appeared essentially the same as before cleaning and annealing.

The tube lengths were put through a series of three cold draws in a second draw cycle, totaling up to $\sim 30 \%$ total reduction with $\sim 10 \%$ reductions per draw, see Table 2. The second draw cycle went well; even for the defected tube. The defects in this tube opened up only slightly, but appeared to be blunting, and the maximum length of cracked material extended slightly as the length of tubing increased (the tubing was about $2.3 \mathrm{~m}$ long at that point).. First hand observations indicated that the material appeared to be drawing better at that point, probably because the material was being made more and more homogeneous due to the deformation/annealing cycles being imparted.

Following the third cleaning and annealing operations, the tube lengths were put through another series of three cold draws in a third draw cycle, totaling up to $-30 \%$ total reduction with $\sim 10 \%$ reductions per draw, see Table 2. Again, the large cracks in the cracked tube opened up slightly, but continued blunting.

However, both tubes now showed indications of very fine-scale transverse (circumferential) surface cracking, like the craze cracking or checking often seen during grinding of some metals. These "craze cracks" 
were fairly uniformly dispersed over the entire surface of the tubes, both on the inner and outer surfaces. They were first noticed after the first draw of the third draw cycle. They could barely be felt with a fingernail $(0.1$ $\mathrm{mm}$ deep. perhaps). This surface effect has been attributed to some contamination picked up during the previous vacuum anneal. A bluish tinge or slight bluegray discoloration of the tubes had been noticed each time they returned from annealing. The craze cracking indications appeared to be only on the surface, however, and the material continued to draw very well.

Visual observations following the fourth cleaning and annealing operations indicated that: a) the craze cracking on both tubes had become very evident; b) some short, fine longitudinal cracks were present on the surfaces of both tubes (these cracks were not extensive and were first noticed with photographic equipment producing a magnified image); c) patches of light $\tan$ to dark brown/black discoloration were present on Tube $\# 2$, with the darkest patches in the immediate vicinity of the through cracks; d) light tan patches were present on Tube $\# 2$ in the non-through-cracked areas initially developed on the outer surface of the tubing as well as in regions containing the more recent fine circumferential cracks; and e) patches of light tan discoloration were also present on Tube \#1 in several places.

Following the fourth cleaning and annealing operations, the defected tube (\#2) was put through the first expansion cycle (see Table 2) expanding the OD of the tube by $\sim 0.25 \mathrm{~mm}$. During expansion step $\# 1,1$ the previously-observed fine-scale transverse surface cracks opened up slightly, and additional fine-scale longitudinal surface cracks of varying degree developed along the length of the tube, on both outside and inside surfaces, with the area of greatest severity being in the badlycracked, highly-strained (brown/black) areas. Expansion was temporarily suspended at that point. A $-25 \mathrm{~mm}$ long section near one end of the heavily-cracked tube $(\# 2)$ was removed for analysis. Metallography and microhardness measurements of sections cut from the removed piece revealed many fine sharp cracks to a depth of $\sim 0.13 \mathrm{~mm}$ running in a longitudinal direction. many blunted ( square-bottomed) cracks to this same depth running in a transverse direction (circumferentially), and a very hard surface layer $\sim 0.13 \mathrm{~mm}$ deep with an underlying material having a hardness typical of the annealed alloy. More than 200 small cracks were examined on the same specimen; all of them had depths in the range of 0.075 to $0.13 \mathrm{~mm}$.

A section of the removed piece was also soaked in liquid nitrogen and bent 180 degrees. Although the surface cracks opened up, the cracks did not propagate across the section. These results were suggestive of the development of a hard, brittle surface region, attributed to oxygen pickup during vacuum annealing.
It was decided to remove $-0.2 \mathrm{~mm}$ from the ID surface of each tube by means of kerosene-lubricated honing. Dry honing was unsuccessful; water-lubricated honing consumed the stones too rapidly. A mechanical guide was made for the honing tool to ensure centering during the operation to avoid preferentially digging into the soft parent metal of the tube below the oxygenated layer. Honing was generally successful, but some traces of surface cracking were still observable in some areas upon completion, but they were not extensive.

Following honing, the tubing ODs were centerless ground to remove $\sim 0.2 \mathrm{~mm}$ of surface material (i.e., the hard layer) prior to continuing with the tubing fabrication.

The second expansion cycle of the two vanadium tubes started with the defected tube ( $\$ 2$ ) first, see Table 2. After expansion $\# 2,2$ some additional growth of the through-cracks and some apparent surface checkering or cracking in the vicinity of the through-cracks was noticed.

Because of this undesirable behavior, the final manufacturing steps were changed. Instead of expanding the \#1 Tube into the steel pipe, it was decided to leave the $V$ tube as-is and to draw down the steel pipe onto the $\mathrm{V}$ tube. The resultant steel pipe OD became $58.6 \mathrm{~mm}$ instead of $60.3 \mathrm{~mm}$; the ID became $53 \mathrm{~mm}$. This compressed the $V$ tube slightly from its $O D$ of $53.2 \mathrm{~mm}$. The final steps to draw down the SS pipe onto the \#1 vanadium tube went very easily.

\section{DISCUSSION AND CONCLUSIONS}

The desired V/SS duplex test section was successfully fabricated. One vanadium tube (\#1) was successfully fabricated and used to make the duplex test section; the second tube contained rather large defects in one half of the tube while the other half was defect free. Two completely unrelated fabrication difficulties were encountered and overcome.

The first difficulty was the appearance and growth of two through-wall crack regions on Tube \#2. The two cracks originally were parallel, each at about a 45-degree angle to the tube axis. These cracks elongated through the continued drawing operation from their initial appearance as simple tears to semi-circular and finally approaching circular shaped defects. At the point where cold working operations on that tube were suspended, they were several millimeters wide. Regardless, the surrounding material continued to draw uniformly. The cracks were probably about $10 \mathrm{~cm}$ apart axially in the original $1245 \mathrm{~mm}$-long bar (approx. $62 \mathrm{~mm} \times 63.5 \mathrm{~mm}$. cross section). 
The cracks are thought to be the result of a localized exhaustion in the material's ductility due to a variation in its as-received structure, i.e., a variation in grain size, inclusions, impurity and/or alloying addition segregation, hot work, and/or other difference in microstructure (e.g., some remaining cast structure perhaps). The problem appeared to result from a large inhomogeneity in the starting material, apparently not present in the other tube blank. This fabrication difficulty was not encountered in Tube \#1 and was restricted to about one half of Tube $\# 2$.

The second problem encountered was the appearance of many fine sharp cracks to a depth of $\sim 0.13$ $\mathrm{mm}$ running in a longitudinal direction, many blunted ( square-bottomed) cracks to this same depth running in a transverse direction (circumferentially), and a very hard surface layer $\sim 0.13 \mathrm{~mm}$ deep with an underlying material having a hardness typical of the annealed alloy. These small surface cracks became significant during the expansion steps following the fourth anneal. These cracks are thought to be due to the development of a hard, brittle surface region, attributed to oxygen pickup during vacuum annealing in the large vacuum furnace. In future V-alloy fabrication efforts, the quality of the vacuum annealing furnace conditions should be carefully evaluated to assure low oxygen and other contaminant levels.

\section{ACKNOWLEDGMENT}

Work supported by the Office of Fusion Energy, U.S. Department of Energy, under Contract W-31-109Eng-38.

\section{REFERENCES}

1. D. L. Smith, H. M. Chung, B. A. Loomis, H.-C. Tsai, "Reference Vanadium Alloy V-4Cr-4Ti for Fusion Application," to be published in the Journal of Nuclear Materials.

2. C. B. Reed, et al., "Fabrication Details of a Vanadium-Stainless Steel Test Section for MHD Testing of Insulator Coatings in Flowing Lithium," ANL/FPP/TM-292, to be published. 